Ciencia y Educación, Vol. 5, No. 1, enero-abril, 2021

ISSN (impreso): 2613-8794・ISSN (en línea): 2613-8808

DOI: https://doi.org/10.22206/cyed.2021.v5i1.pp175-188

\title{
Identidades docentes en Paraguay: investigación educativa basada en artes ${ }^{\mathrm{b}}$

\author{
Identities of teachers in Paraguay: arts-based educational \\ research ${ }^{\mathrm{c}}$
}

Ricard Huerta ${ }^{a}$ ORCID: 0000-0002-1430-3198

Recibido: 26/02/2020 • Aprobado: 18/05/2020

Cómo citar: Huerta, R. (2021). Identidades docentes en Paraguay: investigación educativa basada en artes. Ciencia y Educación, 5(1), 175-188. https://doi.org/10.22206/cyed.2021.v5i1.pp175-188

\begin{abstract}
Resumen
En este trabajo presentamos los resultados del proyecto Mujeres Maestras, un proyecto de investigación internacional con quince años de trayectoria, que busca, mediante las artes, elaborar un discurso visual que se convierte en homenaje al colectivo de las maestras. Tras presentar las características de esta investigación basada en las artes y la trayectoria del proyecto a nivel internacional, nos centramos en el caso concreto de la experiencia del Paraguay. En Mujeres Maestras del Paraguay se presenta la creación artística como herramienta de construcción de narrativas personales y colectivas. El trabajo muestra una selección de piezas artísticas del proyecto, así como algunos relatos de las propias maestras.
\end{abstract}

Palabras clave: educación; arte; investigación; narrativas de mujeres; docencia.

\begin{abstract}
In this work we present the results of the Women Teachers project, an international research project with fifteen years of experience, which seeks to elaborate a visual discourse that becomes a tribute to the teachers' collective. After an introduction to the characteristics of this arts-based research, and the trajectory of the project at the international level, we focus on the specific case of the Paraguayan experience. In Women Teachers of Paraguay, artistic creation is presented as a tool for the construction of personal and collective narratives. The work shows a selection of artistic pieces from the project, as well as some stories from the teachers themselves.
\end{abstract}

Keywords: Education; art; research; women narratives; teaching.

\footnotetext{
a Universitat de València, España. Correo-e: ricard.huerta@uv.es

b Este trabajo forma parte del proyecto "trans-making" RISE (734855-H2020-MSCA-RISE-2016) (2017-2020), con financiación del European Union's Horizon 2020 Research and Innovation Programme Marie Skłodowka-Curie grant agreement n ${ }^{\circ} 734855$. El autor cuenta con todos los permisos para reproducir los nombres y fotografías en el presente trabajo.

c This work is part of the RISE "trans-making" project (734855-H2020-MSCA-RISE-2016) (2017-2020), with funding from the European Union's Horizon 2020 Research and Innovation Program Marie Skłodowka-Curie grant agreement $\mathrm{n}^{\circ} 734855$. The author has all the permissions to reproduce the names and photographs in this work
} 


\section{Introducción}

Como profesionales de la formación de docentes, desde que se inició el proyecto Mujeres Maestras en 2005 hemos intentado reivindicar el papel de las docentes en el entramado social, cultural y político. Potenciamos un mayor acercamiento entre entidades que en numerosas ocasiones viven ajenas a sus propias realidades, tejiendo así redes de compromiso e interacción (universidad, escuela y museo), de modo que generamos sinergias altamente productivas y sensibles (Ramon, 2019). El Proyecto Mujeres Maestras, generado por el grupo CREARI de Investigación en Pedagogías Culturales (GIUV2013-103) de la Universitat de València (España), plantea una investigación artística y educativa que ha recorrido diferentes países, entre ellos Argentina, Bélgica, Brasil, Chile, Colombia, Cuba, Ecuador, España, Perú, Portugal y Uruguay.

El Proyecto Mujeres Maestras es una experiencia de corte artístico y educativo, que indaga en las narrativas personales de las maestras que participan (Rivas et al., 2012), enfatizando en la metodología de la cultura visual. La metodología consiste en analizar las narrativas personales de cada maestra entrevistada, conociendo y compartiendo su realidad durante un tiempo como observadores participantes. Tras ser partícipes de dichas vivencias, y a partir de la recogida de datos correspondiente, proponemos un ejercicio artístico mediante el cual trasladamos a pinturas, dibujos, fotografías y videos la experiencia vivenciada. La metodología es de carácter eminentemente cualitativo y de corte artístico. En función de las posibilidades, la experiencia en cada colegio se desarrolla en tramos temporales que pueden durar entre una semana y quince días. Se trata de acercarnos al máximo a la vida cotidiana y al pensamiento de las maestras, mediante imágenes y textos, implicando al alumnado en las tareas creativas, y en la representación de sus docentes.

Este trabajo se centra en la experiencia desarrollada en Paraguay, de la mano de la Universidad Columbia del Paraguay y del Centro Educativo Los Laureles. Este proyecto nos aproxima a las intenciones que se vienen detectando en muchas de las investigaciones internacionales, de destacar la presencia de las mujeres en lugares estratégicos, como los museos o la universidad. El hecho de introducir la exposición Mujeres Maestras en escenarios como museos o universidades de cada país permite alentar avances, orientados a los postulados que defienden movimientos globales como MeToo u otras interesantes iniciativas, que en cada ciudad permiten detectar innovaciones feministas en defensa de los derechos de las mujeres, con acciones de todo tipo, rescatando así de la invisibilidad el papel clave de las mujeres en el mundo de las artes (Albero-Verdú \& Arriaga, 2018), pero también en el ámbito educativo (Albero-Verdú, 2017).

\section{Pedagogías artísticas que integran univer- sidad, escuela y museo}

La iniciativa que presentamos es innovadora y arriesgada, ya que parte de la premisa de explicar mediante imágenes una serie de efervescencias creativas y pedagógicas, incorporando elementos del patrimonio escolar, para acercarnos a la realidad del colectivo de docentes escolares, combinando la Investigación Educativa Basada en la Artes, de modo que los resultados son básicamente imágenes y obras de creación artística.

Las narrativas personales de las maestras implicadas constituyen una de las fuentes más importantes y fiables para la recogida de datos (Stake, 2005). Otro aspecto que queremos destacar es la importancia que aquí adquieren las imágenes, tanto las creadas por el artista como las que son elaboradas por el alumnado escolar. Gracias a la grabación de las entrevistas disponemos de documentos especialmente valiosos, ya que se trata de relatos que integran la creación artística, la producción audiovisual y la praxis educativa (Huerta, 2018). Las cuestiones de identidad delimitan el espacio de cada estudio realizado. En el caso del Paraguay, impacta el papel decisivo de las mujeres en las constantes reconstrucciones del país (Secretaría Nacional de Cultura, 2016). En consonancia con estas ideas, rememoramos las palabras del profesor Erich Kunhardt:

Crear desafía esa estructuración tradicional, no hay una mecánica para ello. Y dado que no hay un enfoque mecanicista para cultivar la ingeniosidad, 
que es la que nos hace crear, lo que nos queda es la opción de desarrollar esta capacidad en asociación con aquellos que puedan estimularla; es ahí donde entra el profesor. (...) el profesor es sumamente importante; porque el profesor no es solamente una persona que ayuda al estudiante en el proceso mecanicista, sino que tiene también que estimular esa otra dimensión, trabajar en ese otro eje, el de la ingeniosidad y la creación. (Kunhardt, 2020, p. 44)

Siguiendo esta línea de acercamiento a los saberes desde la creatividad y las artes, enlazamos nuestro interés investigador por la realidad de las docentes, compartiendo intereses con investigadoras que también buscan elementos identitarios entre las mujeres maestras, como es el caso de las autoras Hernández Mella, Pacheco-Salazar, Liranzo Soto y Jiménez Soto, cuando al defender el concepto de metáfora, aluden a la posibilidad de encontrar relatos interesantes en el discurso de las mujeres docentes:

Las metáforas revelan concepciones y creencias arraigadas que tenemos sobre nuestra propia historia de vida y nuestro quehacer profesional. Por tanto, su estudio es entendido como una importante estrategia para la investigación educativa y para propiciar procesos de reflexión y cambio en el personal docente. (Hernández et al., 2018, p. 53)

Teniendo en cuenta que las posibilidades de interpretar la realidad de las docentes pueden realizarse desde cualquier disciplina, en nuestro caso incidimos en la investigación artística, un modelo de pedagogía creativa en la que los procesos son tan importantes como los resultados, que son imágenes y obras de arte. Todo ello lo llevamos a cabo defendiendo el contacto personal con las maestras, algo que también valoran otros autores que, al igual que nosotros, trabajan en la formación inicial del profesorado: "Los futuros docentes deben prepararse para enfrentar el entorno laboral, muy diferente al que existía hace una década. Las realidades demandan un trabajo innovador y la puesta en escena de habilidades que promuevan un estilo creativo". (Monterroza, Buelvas-Solórzano y Urango-Arrieta, 2019, p. 40)
Si bien los procesos artísticos resultan más difíciles de encajar en los modelos tradicionales de indagación pedagógica, en la última década hemos avanzado en el campo de la acción pedagógica desde las artes (Rolling, 2017; Huerta, 2019).

Cuando utilizamos la creación artística como medio expresivo generamos una reivindicación de orden social, cultural y político (Huerta, Domínguez y Barbosa, 2017). El hecho de escribir el nombre de cada maestra en su retrato está vinculado a nuestro interés por el alfabeto en tanto su forma gráfica (Huerta, 2020). La relación directa entre el aprendizaje de la escritura y la cultura escolar es algo que no pasa desapercibido a quienes trabajan desde o sobre la educación artística, ya que el alfabeto transciende las materias del curriculum, tal y como lo exponen Baez y D’Ottavio:

La alfabetización es un problema escolar que trasciende a la escuela como institución. Constituye un tema central que es posible redimensionar desde distintas perspectivas: por un lado, en términos de las prácticas y saberes que la cultura letrada de hoy exige; por el otro, la resignificación de temas y problemas sobre la temática, a partir de los aportes de distintas disciplinas. (2020, p. 33)

Entendemos la Investigación Basada en las Artes desde la importancia de las imágenes. En este sentido, las fotografías del presente artículo no son únicamente un "acompañamiento" al texto, sino que se convierten en relato de investigación por derecho propio. Las fotografías nos sirven asimismo para documentar las problemáticas de colectivos vulnerables (Melo de Lima Santos, 2017). En nuestro caso, además, forman parte del relato investigador, siendo tan importantes como el propio texto, puesto que sin las imágenes resultaría difícil comprender la actividad desarrollada.

\section{Trayectoria internacional del proyecto Mujeres Maestras}

El proyecto ha ido creciendo, enriqueciéndose y actualizándose, desde que empezó hace 15 años en Valencia, España. Siempre partimos de una estructura similar, lo que nos interesa es unir las miradas particulares del alumnado, del artista y de las mujeres a 
quienes entrevistamos. Todo ello desde la perspectiva de la educación artística. Nos interesa la vida de las mujeres que se dedican a la docencia del mismo modo que nos interesa reivindicar su papel fundamental en la sociedad. Pensamos que no está suficientemente reconocido el trabajo de las maestras, y por ello demandamos una mayor atención hacia sus realidades.

Desde la Investigación Educativa Basada en las Artes, siguiendo las estructuras marcadas por teóricos relevantes que defienden esta metodología de investigación (Rolling, 2017), procesamos elementos creativos que son básicamente imágenes, y reflexionamos por, para y desde las imágenes. Como profesores de educación artística para la formación de docentes, durante décadas hemos podido comprobar que la mayoría de nuestro alumnado son mujeres. El hecho de haber compartido todo este tiempo con educadoras resultó determinante para iniciar el proyecto Mujeres Maestras, que sigue vigente como work in progress, en tanto que acción artística. Se trata de un homenaje a las educadoras, a las mujeres que hilvanan su discurso como maestras desde la responsabilidad, el anonimato y el trabajo bien hecho.

Tras haber recorrido varios países y entrevistado a cientos de maestras, hemos conseguido elaborar un discurso relevante por su trayectoria y resultados. Se trata siempre de acercarse al particular mundo de las docentes de forma sensible y con especial atención a sus identidades. Al conocer de cerca sus contextos, se entrelazan las historias y vivencias, desde la convicción de que ser maestra es una declaración de principios y un compromiso como mujer. Por todo ello, esta iniciativa creativa se convierte en un ejercicio que parte de lo profesional, pero que atañe sin duda a lo personal. Se vive el conocimiento, la experiencia, el respeto, la paciencia, la motivación, la constancia, y desde luego la implicación de la persona. Se trata de elaborar una mirada crítica hacia todo lo que se construye culturalmente en torno a la visibilidad (e invisibilidad) del colectivo docente. La interpretación de estas vivencias se traduce en obras de arte que inciden en cada una de estas maestras.

\section{Figura 1}

Letra C de la serie "Alfabeto de las Maestras de Europa"

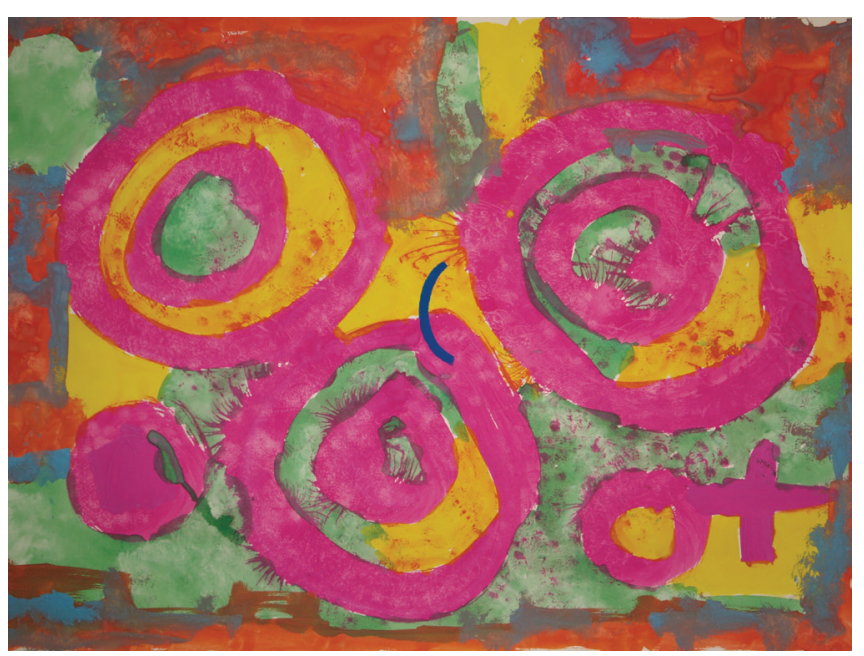

Cuando se presentó el proyecto Mujeres Maestras en la sede del Parlamento Europeo, en Bruselas, elevábamos a la máxima instancia política europea el debate de la importancia (o no) del colectivo profesional de las mujeres docentes. La muestra se ubicaba en el Espace Atrium, la sala de exposiciones más importante el Parlamento Europeo, y articulaba desde las artes, numerosas propuestas de mejora para la situación laboral de las docentes. No podemos perder de vista que en la mayoría de casos estamos hablando de personas que trabajan muchas horas por unos salarios muy precarios (Donaire, 2012) 
Figura 2

Pintura dedicada a Marcela Rojas de la serie "Mujeres Maestras de Chile"

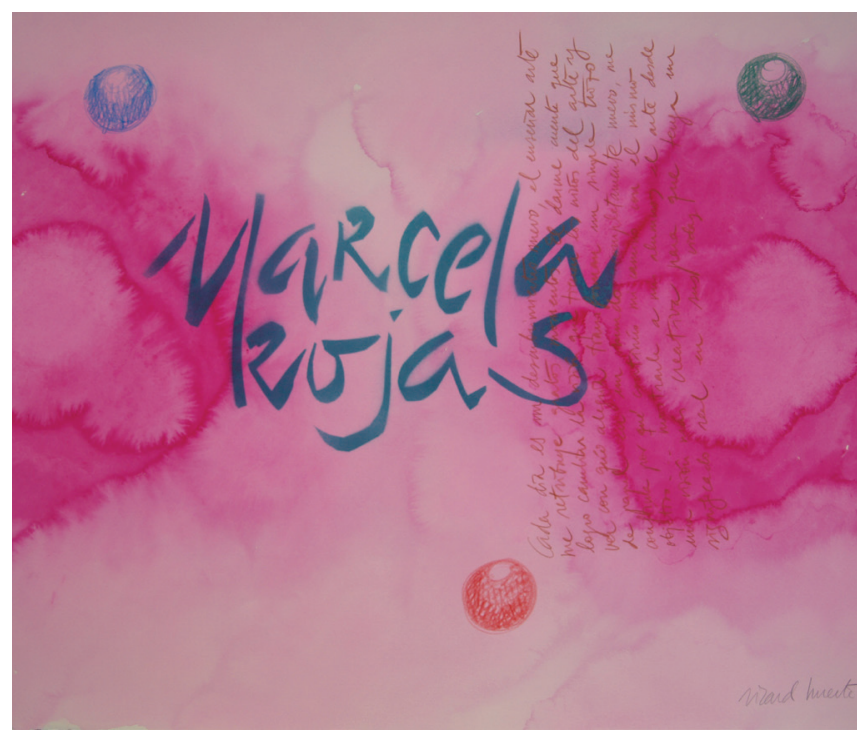

Hemos desarrollado la investigación en países que viven momentos importantes, como es el caso de Chile, que propende a las reivindicaciones educativas. Pudimos presentar el proyecto en el Museo Artequín de Santiago de Chile. Las conversaciones y entrevistas con las maestras chilenas resultaron muy intensas, en parte debido a la realidad que ha vivido y sigue viviendo este país, en el que la sombra de la dictadura continúa pasando factura al devenir democrático. Algunos relatos de mujeres que sufrieron ellas mismas, o vieron como desaparecían sus familiares más cercanos, nos acercan al terror y sufrimiento que padecieron. También recogimos declaraciones llenas de esperanza y de confianza en la educación. Entre sus mayores anhelos destaca siempre la posibilidad de mejorar como sociedad y como personas, para alcanzar así un bienestar y una situación realmente democrática.
Figura 3

Pintura dedicada Gladys Barrios. Serie "Mujeres Maestras de Uruguay"

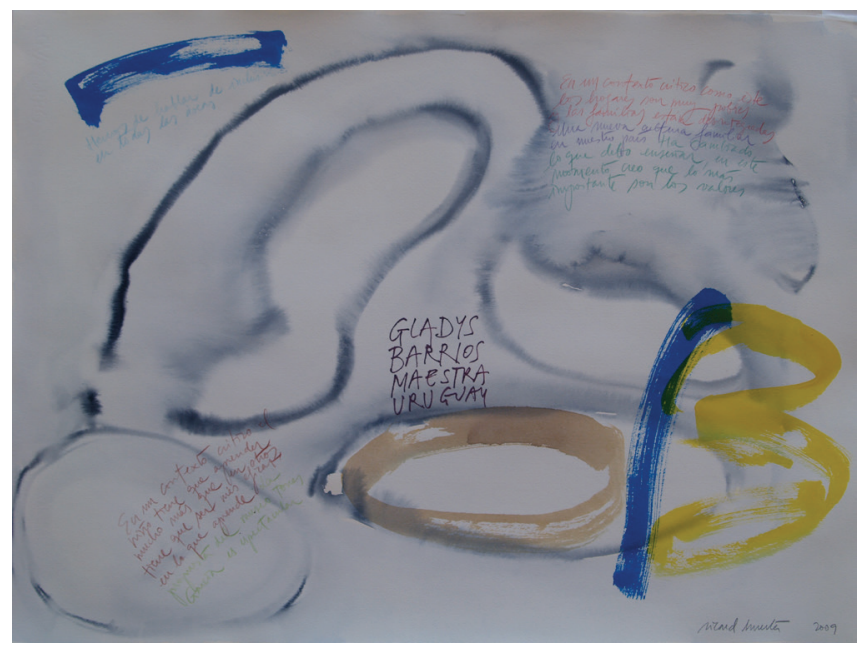

Otra experiencia significativa, fue el proyecto Mujeres Maestras en Uruguay que, tras haber compartido ideas con las maestras, se optó por utilizar el color gris en las pinturas, debido a que Montevideo es una ciudad donde durante prácticamente todo el invierno el gris inunda el cielo y la luz de la capital uruguaya. Escuelas públicas y privadas accedieron a participar en el proyecto, destacando el Centro Educativo Ciudad Vieja, que capitaneó la celebración con eventos que incluso ocuparon las calles de la ciudad, con festivales musicales y desfiles escolares. Las familias del alumnado se sumaron a la celebración, ya que se trata de un país con una gran tradición democrática y un inmenso deseo de mejorar en lo pedagógico (Álvarez-Blanco, 2019). Se programaron actividades, con una alta participación de todos los actores implicados en el contexto escolar: alumnado, profesorado, familias, administración educativa. En este país a las docentes se les regala una joya cuando terminan la carrera, un anillo o un 
broche en el que aparece el símbolo de las maestras: la abeja. Trabajadoras, anónimas, capaces de coordinarse en equipo, como las abejas. De hecho, este símbolo aparece tanto en el Museo de la Educación como en la Biblioteca Pedagógica, ambas instituciones regentadas exclusivamente por maestras.

\section{Figura 4}

Pintura dedicada a la docente María Jesús Agra. Serie "Dones Mestres"

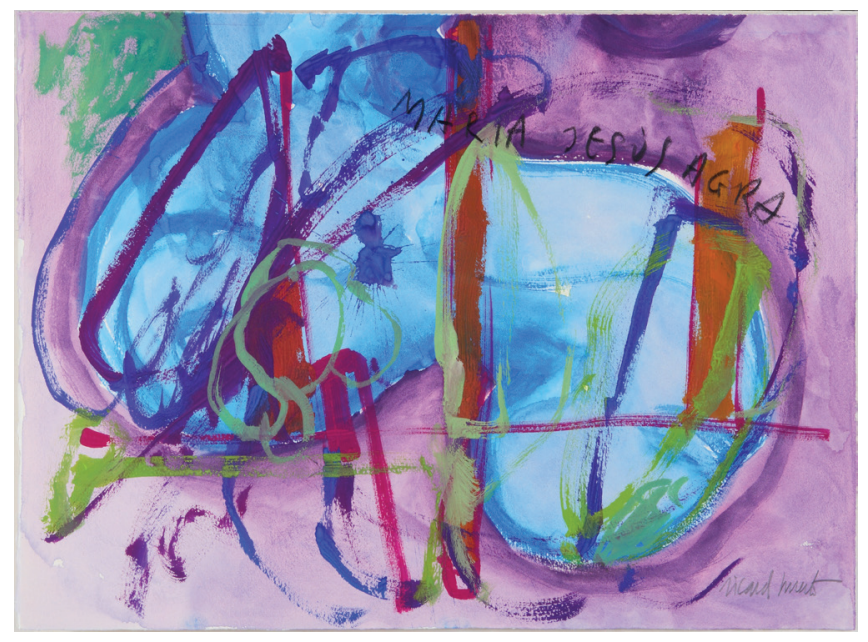

Por otro lado, la experiencia del recorrido del proyecto en España se ha centrado en museos universitarios. En la Universidad de Alicante, por ejemplo, los niños instalaron sus dibujos en las paredes, comentándolos. Pudimos comprobar hasta qué punto fascinaba al alumnado poder ver expuestos sus trabajos en las paredes del museo universitario. Durante las semanas que la muestra estuvo expuesta al público, fueron numerosas las familias que asistieron a ver los dibujos de los más pequeños. Esta es una constante de las exposiciones de Mujeres Maestras, ya que resultan atractivas para los familiares del alumnado que expone sus dibujos. Con ello conseguimos atraer a un tipo de público que probablemente no es asiduo a los museos, pero que sí se sienten atraídos por visitar una muestra en la que participan con dibujos propios sus hijas, sus nietos, o sus sobrinas. Las familias y más gente vinculada por amistad asisten a la exposición para poder ver in situ los dibujos del alumnado escolar, de modo que cada nińa o cada alumno les puede mostrar y explicar su propia obra.

\section{Figura 5}

Pintura dedicada a Itziar Zubizarreta de la serie "Alfabet de les Mestres"

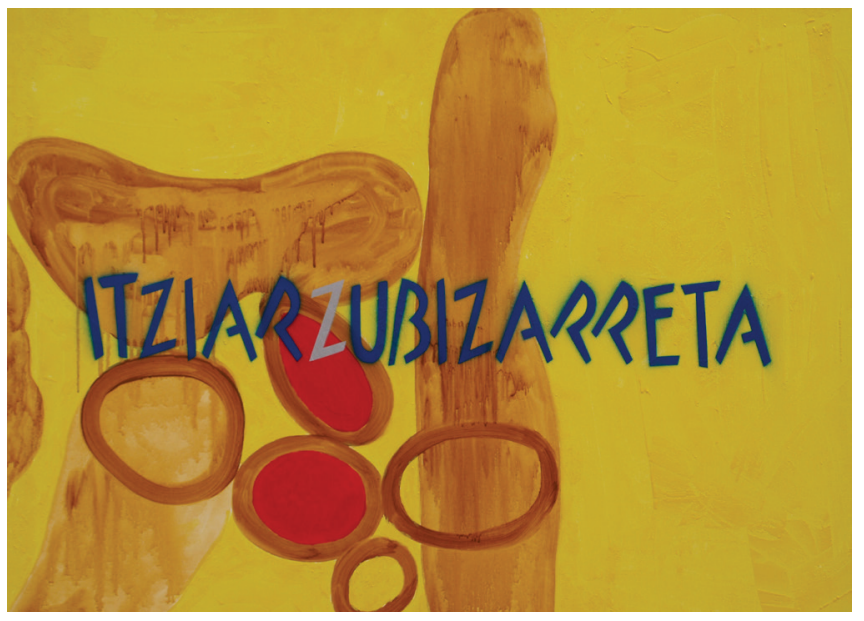

\section{Figura 6}

\section{Obra dedicada a Beatriz Elena de la serie "Mujeres Maestras de Colombia"}

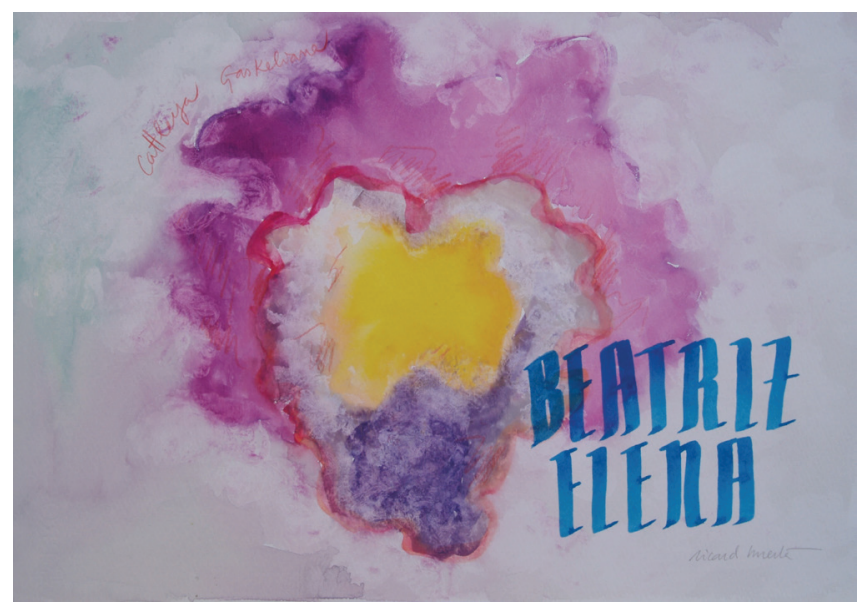

Para Pilar Méndez Rivera, ser docente en Colombia plantea grandes dificultades de todo tipo, debido a la situación peculiar del país, ya que "su participación en la vida pública, en estrecha relación con otros sujetos, le obliga a posicionarse en la compleja red de relaciones de poder que se tejen alrededor de la confluencia de los 
campos político, educativo y social" (Méndez, 2016, p. 18). A las problemáticas laborales del colectivo se suman elementos que dificultan el ejercicio profesional, como la situación precaria de las familias del alumnado, o incluso el mal estado en que se encuentran las instalaciones donde se trabaja. En los países donde se ha presentado el proyecto Mujeres Maestras, la inmensa mayoría de profesionales de la enseñanza que trabajan en los niveles de educación infantil y primaria son mujeres. Esto tiene mucho sentido si comprobamos que la "imagen" que tenemos del colectivo docente en estas etapas educativas es una imagen en femenino. A partir de aquí, el relato visual toma tintes de género, ya que el hecho de disponer de representaciones gráficas hechas por el alumnado, por el artista y por las propias mujeres al ser entrevistadas en video, nos acerca a diversas cuestiones del tipo: ¿Cómo vemos a las maestras? ¿Cómo se ven ellas mismas?, e incluso ¿Cómo les gustarías ser vistas? Se hace hincapié en problemáticas como la conciliación familiar y laboral (Alonso-Sanz, 2016).

\section{Figura 7}

Obra dedicada a Mila Mendivil. Serie "Mujeres Maestras del Perü"

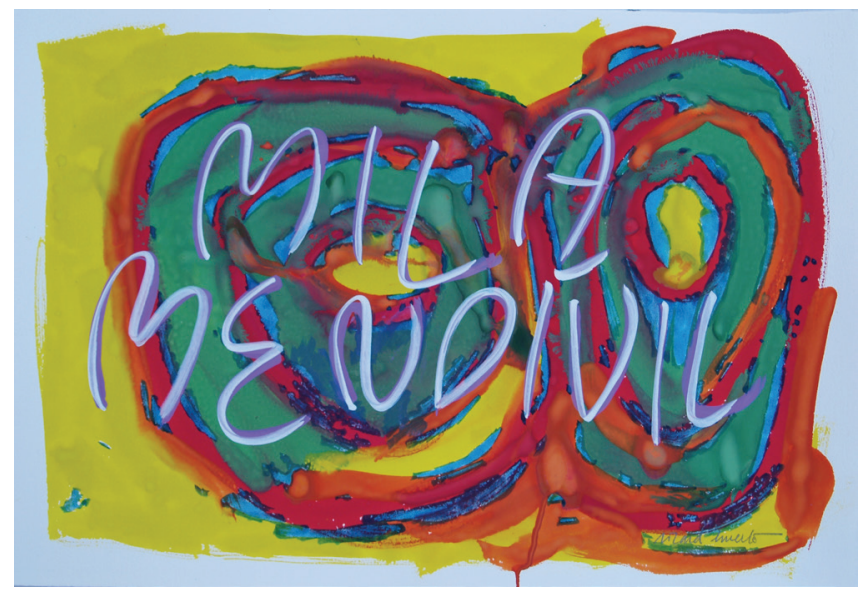

\section{Experiencia creativa desarrollada en Paraguay}

En el presente trabajo contamos con la participación de maestras de centros educativos de distintos barrios de Asunción, la capital del Paraguay. Hemos mantenido diálogos con ellas y hemos conocido sus centros educativos acercándonos a cuestiones que llegan a ser de índole personal, atendiendo a factores que van más allá de las problemáticas sociales o laborales, y que pueden tener repercusiones emotivas, importante en la labor educativa de estas profesionales (Rolling, 2017).

En este proceso artístico, llevado a cabo durante 2018 y 2019, utilizamos como base la observación participante, indagando en las inquietudes y el espíritu que transmiten las profesionales de la docencia, interesándonos por mujeres de diferentes edades y estamentos sociales. El diálogo con ellas se convierte en el hilo conductor del discurso artístico, que nunca pierde de vista la esencia educativa de su planteamiento inicial. Las formas, los grafismos, los colores y las texturas son aliados perfectos para documentar nuestro interés por sus realidades, renovando así la percepción que tenemos de las maestras.

Las docentes entrevistadas reconocen la necesidad de integrar las artes en la escuela, dado que son una herramienta poderosa para la formación del alumnado, para el desarrollo de un espíritu crítico, para generar ciudadanía y para el fomento de la creatividad. En última instancia, defendemos el concepto de docente como intelectual (Giroux, 2013), animando la presencia del arte y las humanidades en las tareas educativas.

\section{Figura 8 \\ Obra dedicada a Claudia Saldivar. Serie "Mujeres Maestras del Paraguay"}

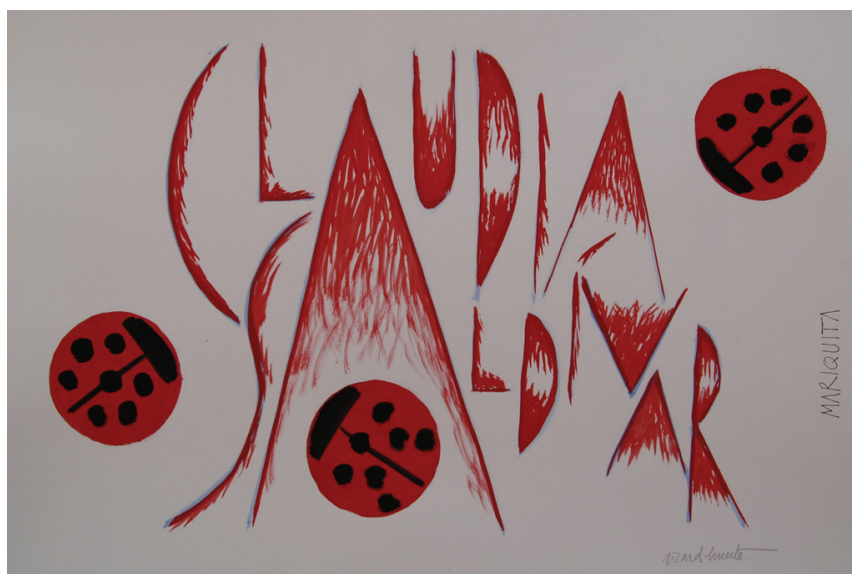


Para retratar a cada maestra, se utilizan las letras que componen su nombre. Estas letras se convierten en concepto visual, ya que incorporan elementos que aluden al carácter significativo que representa cada una de las docentes. El alfabeto, un elemento tan vinculado al mundo escolar, adquiere aquí valor artístico, de modo que las letras nos transmiten el espíritu de cada docente interpretada (Huerta, 2020).

En el caso de los dibujos que hacen los niños y las niñas, las maestras son interpretadas como figuras clave en su vida. Se trata de retratos cargados de sentimientos. Los más pequeños inciden en las características que definen a cada maestra, no solamente en lo referido a su aspecto (peinado, forma de vestir, movimientos característicos), sino también en su manera de ser, la mayoría de las veces con alegría (grandes sonrisas, corazones, colores vivos, frases cariñosas), pero también expresando su papel orientador (orden, trabajo, resiliencia, compromiso, paciencia, constancia). En la mayoría de las ocasiones detectamos admiración y reconocimiento. Entramos en los parámetros de la investigación educativa implicada, combinando elementos de orden significativo, pero reconociendo al mismo tiempo la vertiente artística como factor clave para acercarnos a lo que vivimos y observamos en directo, en nuestra labor educativa (Elliott, 1990).

\section{Figura 9}

Laura Maldonado junto a la obra de la serie "Mujeres Maestras del Paraguay"

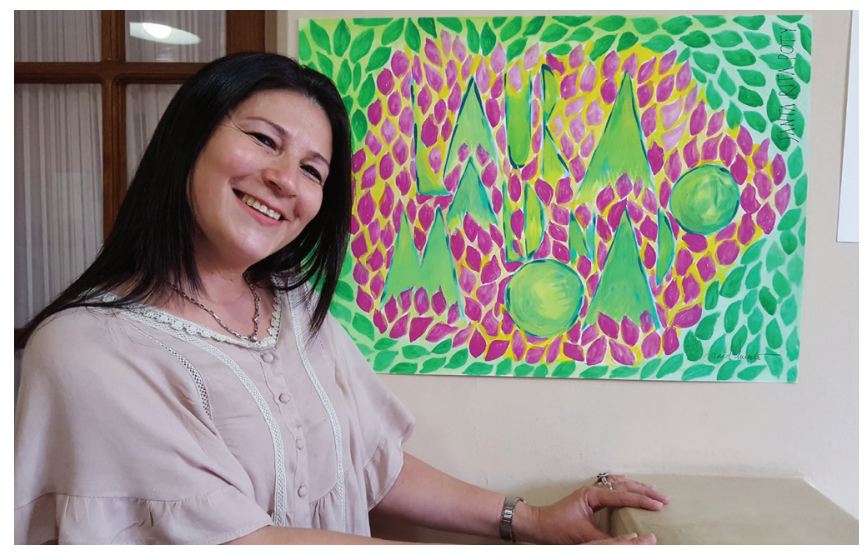

En el caso del Paraguay, debido a la contundente presencia de la naturaleza en el paisaje, le pedimos a cada maestra que nos dijese cuál era su flor, planta, árbol o elemento natural preferido. Laura Maldonado eligió la Flor de Santa Rita (buganvilla), por lo que esta flor es el motivo de la composición del retrato. Ella dirige el nivel inicial del CEL (Centro Educativo Los Laureles), donde ha desarrollado su labor durante los 24 años que viene ejerciendo. Algunas maestras eligieron animales (gato, búho, mariquita, abeja), mientras que otras optaron por elementos conceptuales vinculados al territorio (la tierra, el horizonte, la arena). Olga Molina nos manifestó su preferencia por la línea del mar al juntarse con el cielo. Como en lengua guaraní el concepto "mar" no es traducible, se optó por "gran agua” (yguasu).

\section{Figura 10}

\section{Olga Molina, pintura de la serie "Mujeres Maestras del Paraguay"}

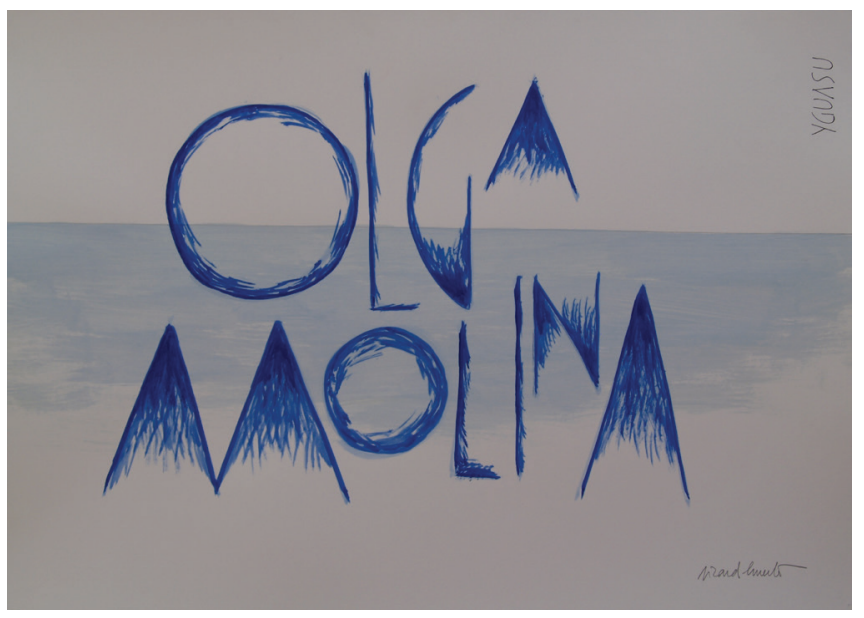

En cada dibujo se expresa, en un lateral, el concepto elegido en lengua guaraní, que es, en esencia, uno de los rasgos decisivos de la cultura paraguaya. Por eso hemos querido dejar constancia de esta potente idiosincrasia en cada pintura de la serie. En esta serie, el árbol con más adeptas fue el tajy (lapacho), expresado en la imagen siguiente: 
Figura 11

Edit Vera. Pintura de la serie "Mujeres Maestras del Paraguay"

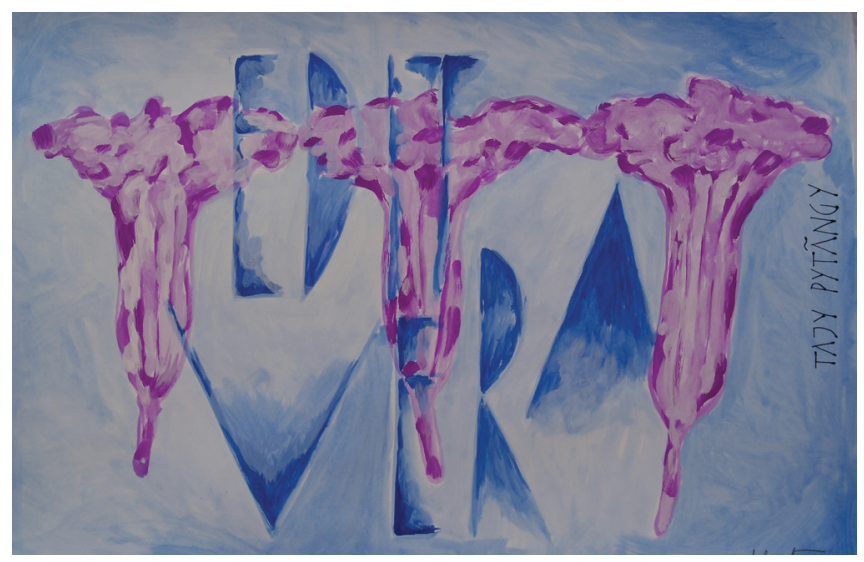

La interpretación de cada maestra, en pintura, está en función de lo que ella transmite, tanto al conversar durante la entrevista, como en sus textos escritos. En esta ocasión, al haber podido compartir durante varias semanas la vida del Centro Educativo Los Laureles, además, como artista he tenido la oportunidad de conocerlas mejor, ya que estuve pintando la serie precisamente en los locales del CEL, dialogando también con el alumnado y con el personal de servicios y administración del centro.

\section{Figura 12}

Espacio del CEL donde se pintaron las obras de la serie

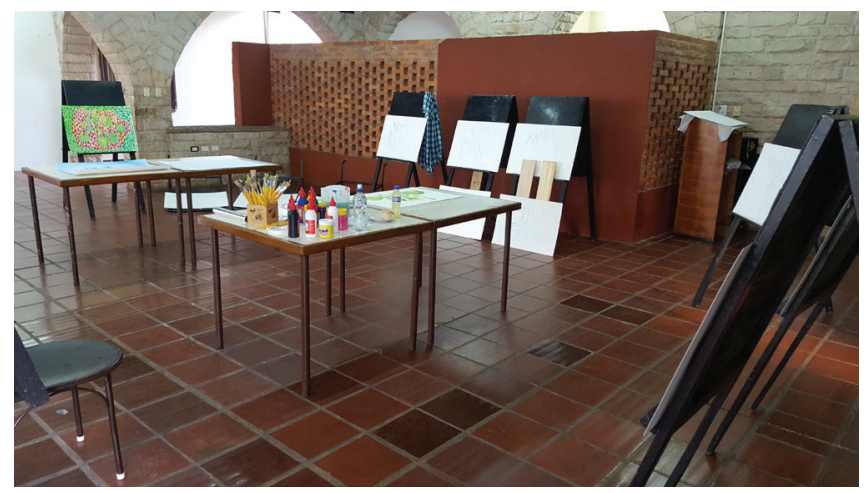

Para la selección de las maestras se tuvo en cuenta que fuesen de diferentes edades y procedencias, habiendo contado con la implicación de tres centros educativos: uno privado, uno público y otro cooperativo. Del CEL Los Laureles participaron: Olga Molina, Claudia Saldívar, Susana Ortega, Margarita Vega, Laura Olivera, Delsy Cristaldo, Beatriz Martínez, Eva Quevedo y Laura Maldonado. Del colegio público Escuela República de Panamá se implicaron las docentes Mariana Villalba, Ofelia Peralta, Edit Elizabeth Vera, Lilian Rosana Escobar, Rosana María Elena y Amalia Pamela Aquino. Por parte de la Escuela Kunumí Areté de Areguá pudimos contar con Julia María Pineda, Lourdes Benítez, Cinthia Karina López, Ana Caballero, Carolina Pederzani y Noelia Buttice.

Las opiniones de las maestras paraguayas quedan expresadas en el video Mujeres Maestras del Paraguay, ya editado, presentado durante la exposición, y pendiente de publicarse en Internet. Además de contar con este documento audiovisual, se realizó un seminario participativo, en el que les pedíamos que relatasen experiencias personales.

\section{Historias y experiencias personales}

Para Laura Maldonado ser docente significa "transmitir ante todo amor al aprendizaje, demostrar en todo momento felicidad y compartir el día a día". Eva Quevedo quiso destacar "la fuerza y el coraje que adquirió cuando fue despedida del cargo como directora general de la última institución en la que trabajaba”, tras lo cual optó por crear y liderar su propio centro educativo.

\section{Figura 13}




\section{Eva Quevedo señalando su retrato en la exposición}

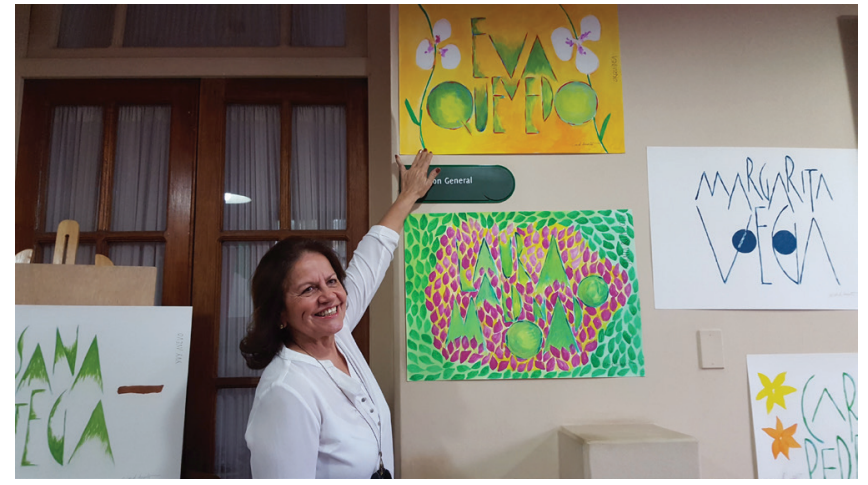

Claudia Saldívar es la única docente de su familia, y para ella es "una profesión fascinante, porque le permite transmitir a los niños lo que sabe, y aprender de ellos". Laura Olivera sintió "desde niña la vocación docente, cuando jugaba a ser profesora con sus hermanas". Siempre quiso trabajar con alumnado con necesidades especiales y con adecuaciones curriculares, lo cual puede llevar a cabo ahora, ya que el CEL es un centro inclusivo.

Desde que era niña, el padre de Beatriz Martínez le inculcó la idea de ser profesora, y ella "jugaba a ser maestra, improvisábamos una pizarra y escribía lecciones para mis amiguitas", ahora tiene 22 alumnos de quinto grado. Por otro lado, Amalia Pamela Aquino, maestra y licenciada en psicología, nos cuenta que ha trabajado durante veinte años en diferentes instituciones públicas y privadas, y considera que en la educación pública se debe dar más importancia al nivel inicial. También, destaca "la sinceridad de los niños al demostrarnos su carińo".

Lourdes Benítez se formó en comunicación y se dedica a la escritura creativa, a la literatura, habiendo optado por participar de la experiencia educativa Kunumí Areté, impartiendo talleres de comunicación.

Noelia Buttice explica que crearon la escuela Kunumí Areté para "acompañar a nuestros hijos y nuestras hijas en su crecimiento, porque queríamos pensar y sentir en comunidad aquello que era importante para nosotros". Ana Caballero, también de Kunumí Areté, estudió diseño gráfico y se dedica a las artes visuales, nos dice: "mi inspiración para trabajar es una escuela de arte a la que fui de niña, la Escuela de Arte Municipal de Asunción, donde conocí a docentes muy interesantes, que trabajaban el arte de manera lúdica, muy inspiradora", lo cual traslada a su tarea educativa mediante cuentos y elementos comunes de la comunidad.

Para Delsy Cristaldo, del CEL, resulta muy inspirador poder impartir comunicación (lengua castellana) al alumnado con diversidad funcional, como es el caso de una alumna con ceguera a quien se siente muy unida, al igual del resto de los nińos que describe como "cajita de sorpresas"; valora positivamente el ambiente de compañerismo del centro.

Lilian Rosana Escobar Caballero, del colegio República de Panamá, profesora y licenciada en Ciencias de la Educación, siendo muy joven se planteó seriamente acceder a un rubro del Estado, si bien estuvo doce años trabajando en instituciones privadas para acceder al puntaje exigido por experiencia. Sus planteamientos nos recuerdan la importancia de la teoría crítica de la enseñanza (Carr y Kemmis, 1988), especialmente cuando se trata de "recibir apoyo significativo de la autoridad educativa, acusar el acompañamiento a los padres, o aumentar la valoración de la sociedad", algo que "para mejorar debe empezar de arriba".

\section{Figura 14}

\section{Lilian Rosana Escobar eligió la rosa (yvoty) como su flor preferida}

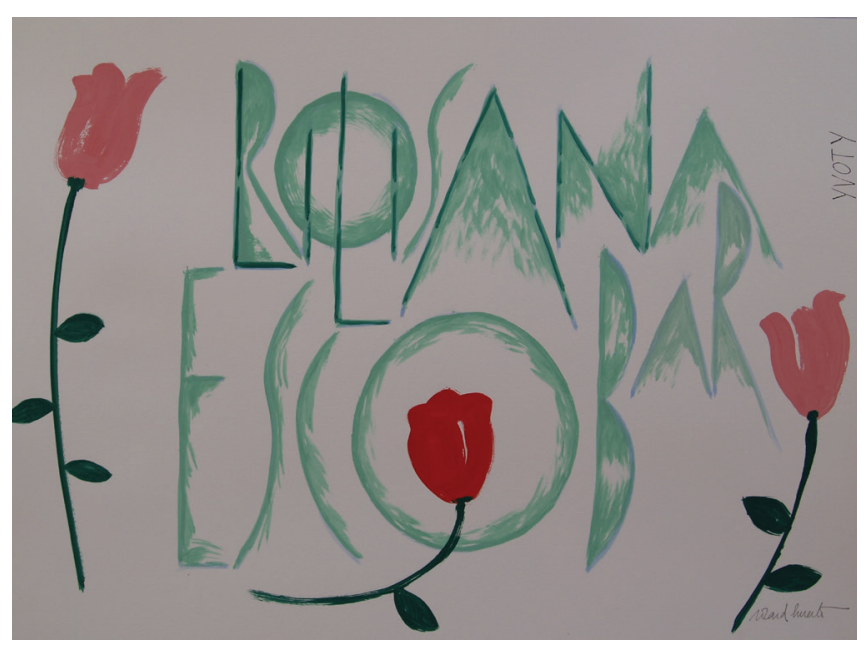

Es importante destacar, que las docentes reclaman 
un mayor reconocimiento, tanto en lo referido al sueldo como en la valoración de las titulaciones, así como una constante capacitación para actualizar conocimientos. En esta línea, Rosana Esquivel, tras veinte años de experiencia docente, reconoce que el desgaste físico y emocional es grande, y se siente muy sola como docente de nivel inicial, cuando comprueba que hay que poner mucho por parte de la maestra, ya que los niños llegan con muchos problemas. Ella reclama más apoyo de los padres y más interés por parte del Estado, especialmente para casos de burnout laboral y salud mental (Zafra, 2017).

\section{Figura 15}

Rosana Esquivel se siente identificada con el color azul (hovy)

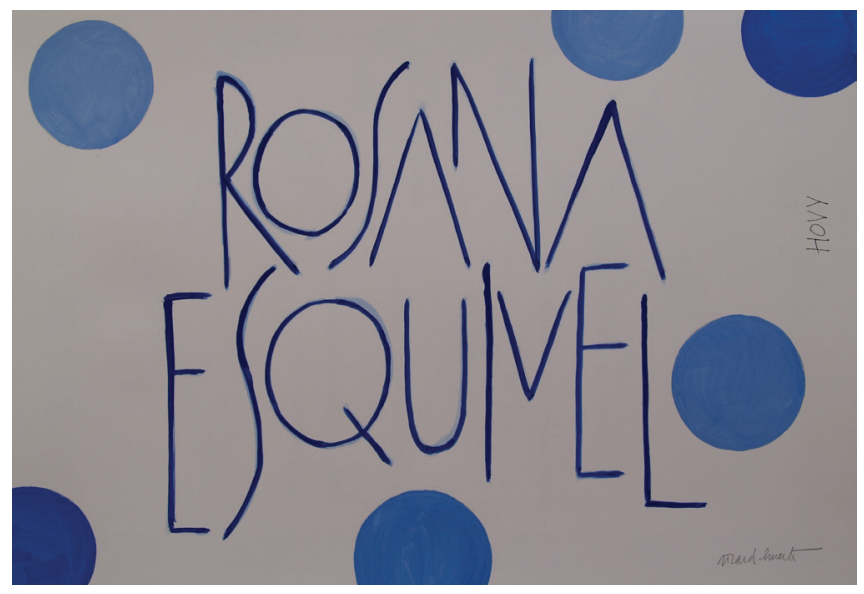

Por otro lado, Karina López, bailarina especialista en danza contemporánea, traslada sus conocimientos sobre las posibilidades expresivas del cuerpo al alumnado de Kunumí Areté. Así mismo, Olga Molina es maestra desde hace 25 años y se ha centrado en la docencia con talleres artísticos, especialmente en artes plásticas, algo que pudo desarrollar como docente del CEL, donde le animaron a estudiar la carrera de artes. Laura Olivera, en cambio, se formó como química y ha tenido que trabajar en otras empresas para poder sostener a sus hijos cuando eran más pequeños, pero finalmente ha vuelto a la docencia, lo que siente que es su mundo. Ella eligió el jazmín como elemento natural predilecto.

\section{Figura 16}

Laura Olivera junto a su retrato tipográfico y simbólico

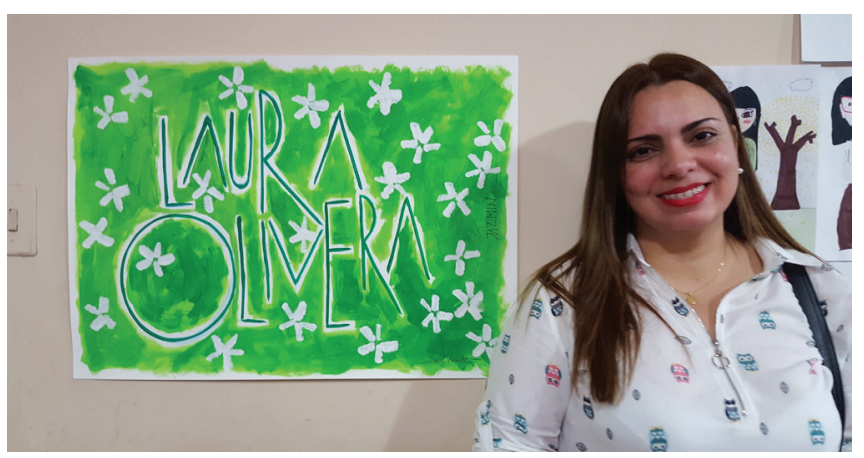

Susana Ortega nos transmite sus impresiones a través de la lengua guaraní, explicándonos que resulta muy complicado traducir al castellano cuando se habla de conceptos o sentimientos propios de esta cultura. Su pasión por la enseñanza y por la literatura le ha empujado a transmitir sus ideas a través de libros y publicaciones, donde se esfuerza por dignificar la presencia de su lengua. En los dibujos de su alumnado reconocemos el carińo con que la interpretan.

\section{Figura 17 \\ La maestra Susana Ortega interpretada por su alumnado}

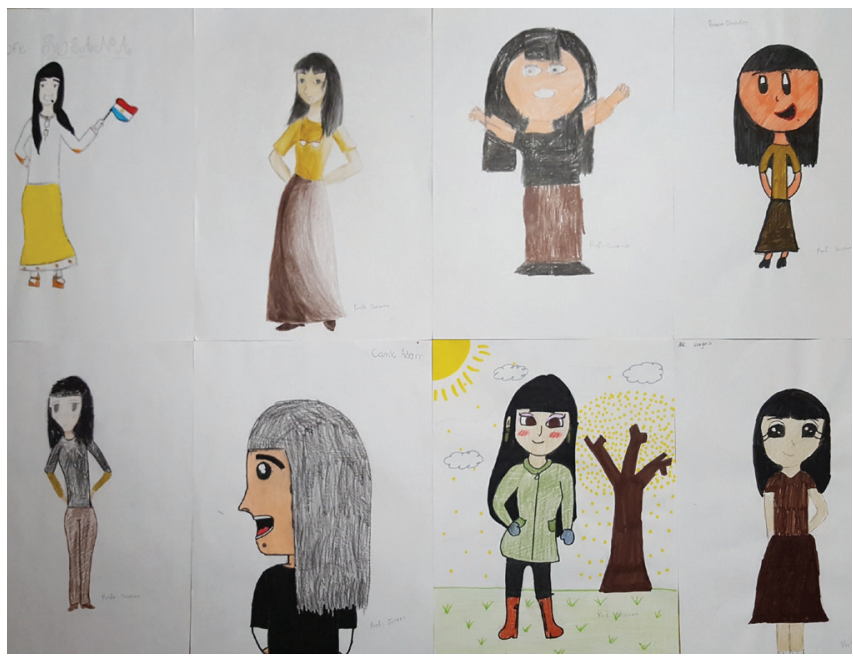

Detectamos en Susana una alta carga de implicación por aquello en lo que cree, ya que además imprime sentimiento y describe de manera vehemente 
ideas, formas y vocablos con los que puede transformar el mundo. Su alegría es contagiosa, sus gestos elocuentes, y su forma de difundir el espacio guaraní resulta emotiva. Eligió la tierra (yvy avevo) como motivo determinante de su preferencia, en relación con el entorno natural.

Para Carolina Pederzani, docente de inicial en Kunumí Areté, es importante "volver a ser una niña más con ellos", refiriéndose al alumnado, ya que "todos tenemos nuestro niño adentro" para crear un "pequeño mundo hermoso". También Julia Pineda, del mismo Kunumí Areté, valora positivamente "el poder estar con los niños al aire libre, escucharles para aprender de ellos, que cualquier cosa pueda ser un aprendizaje”. Mientras tanto, Ofelia Peralta, hija de maestra, ejerce en tercer grado de básica en la escuela República de Panamá, y si bien opina que "se aprende jugando", considera que "la profesión de educadora se debe ejercer de vocación", ya que "si no se ama esa profesión, y más en el Paraguay, resulta muy sacrificada". Ofelia, agrega que "la sociedad no reconoce nuestra labor" (Freire, 2015).

Sin embargo, para Claudia Saldívar, uno de los temas clave es el de la inclusión, precisamente porque todo el alumnado se beneficia al tener niños y niñas compartiendo sus experiencias con compañeros y compañeras que necesitan atenciones específicas. Incluso nos comenta el hecho de que Álvaro Martínez, que trabaja en el Teletom, ha sido alumno suyo. Margarita Vega, por su parte, como Licenciada en Ciencias de la Educación, nos explica la enorme diferencia que supone trabajar en un centro público o en una escuela privada, ya que ella, a lo largo de 15 años, ha podido conocer ambas realidades. Un caso peculiar es el de la artesana Rosa Segovia, tejedora de ponchos de 60 hilos (una de las pocas que quedan), quien además decidió estudiar Pedagogía, y ahora es maestra licenciada.

\section{Reflexiones finales}

Haber conocido en directo a un grupo de maestras del Paraguay nos ha permitido establecer criterios propios sobre los modelos educativos del país, así como generar una experiencia enriquecedora al entrevistarlas y representarlas mediante pinturas de índole tipográ- fica (Huerta et al., 2018). Este conocimiento directo ha posibilitado un acercamiento a la actividad de las mujeres maestras. Ahora disponemos de un audiovisual en el que tenemos editadas las 21 entrevistas. También se han realizado las 21 pinturas de retratos tipográficos, además de contar con centenares de dibujos que los niños y las niñas han elaborado de sus profesoras. Nos hacemos eco de las quejas y reivindicaciones de las docentes, que piden recibir más atención, tanto económica como de reconocimiento laboral y artístico. El bagaje cultural paraguayo está tremendamente vinculado a las artesanías (Capdevila, 2016), lo cual nos acerca a las reflexiones de tipo estético, cultural, económico, histórico y político (Escobar, 2011). Estamos a tiempo para celebrar las diversidades, tanto de las maestras como de las artesanas, y serán los poderes públicos quienes tendrán la última palabra si deciden (o no) apoyarlas.

El Paraguay ha visto renacer de las cenizas su historia y su memoria gracias a las mujeres, al menos en dos ocasiones (la Guerra de la Triple Alianza y la Guerra del Chaco). En ambos casos han sido las mujeres quienes han originado este renacimiento; ellas son las responsables de este doble resurgir. Sin idealizarlas, pero tampoco eliminándolas del espacio público, lo que hacemos es reconocer su esfuerzo, homenajearlas por su labor y transmitir estas enseñanzas a los niños y las niñas mediante actividades artísticas. Visibilizamos el trabajo de las mujeres, dignificándolo y apoyándolo.

Finalmente, se sugiere animar al profesorado de todos los niveles educativos a utilizar las artes y la creatividad artística como recurso para tratar temas de índole social y de reivindicación de derechos. Crear imágenes en educación supone algo más que expresar o representar. La creación artística en la escuela puede ofrecer también un aliento para reconocer el valor de ciertos colectivos que merecen más atención y respeto. Las mujeres que se dedican a la enseñanza son profesionales, a quienes los poderes políticos y administrativos deben atender con mayor respeto y eficacia. Hacer visible sus realidades, generando imaginarios artísticos, nos puede ayudar a comprender mejor su labor educativa, así como su importante papel en la sociedad. 


\section{Referencias}

Albero-Verdú, S. A. (2017). La perspectiva de género en el ámbito educativo de los museos y centros de arte españoles.(Tesis Doctoral de la Universidad Pública de Navarra). Pamplona.

Albero-Verdú, S. A. y Arriaga, A. (2018). Educación con Perspectiva de Género en Museos Españoles. Enfoques y Discursos. Géneros. Multidisciplinary Journal of Gender Studies, 7(1), 1531-1555. http://dx.doi.org/10.4471/generos.2018.2921

Alonso-Sanz, A. (2016). Conciliación de la vida estudiantil, familiar y laboral de una madre universitaria. Revista de Antropología Experimental, (16), 223-233.

Álvarez-Blanco, L. (2019). Modelos teóricos de implicación educativa familiar: responsabilidades compartidas entre centros educativos, familias y comunidad. Aula Abierta, 48(1), 19-30. http:// dx.doi.org/10.17811/rifie.48.1.2019.19-30

Baez, M. y D' Ottavio, M. E. (2020). La diversidad en el aula: el desafío de interpretar la singularidad de los procesos de alfabetización inicial. Ciencia y Educación, 3(3), 31-40. https://doi. org/10.22206/cyed.2019.v3i3.pp31-40

Capdevila, R. (2016). Julián y Josefina: de la indagación americanista al descubrimiento del arte popular paraguayo. Cuadernos Salazar (4), 28-33.

Carr, W. y Kemmis, S. (1988). Teoría crítica de la enseñanza. La investigación-acción en la formación del profesorado. Ediciones Martínez Roca.

Donaire, R. (2012). Los docentes en el siglo XXI: ¿empobrecidos o proletarizados? Siglo XXI Editores.

Elliott, J. (1990). La investigación-acción en educación. Morata.

Escobar, T. (2011). El mito del arte y el mito del pueblo. Cuestiones sobre arte popular. CAV Museo del Barro.

Freire, P. (2015). Pedagogia da autonomia: saberes necessários à prática educativa. Editorial Paz e Terra.

Giroux, H. (2013). 'La pedagogía crítica en tiempos oscuros'. Praxis Educativa, XVII(2), 13-26.

Hernández Mella, R., Pacheco-Salazar, B., Liranzo Soto, P. y Jiménez Soto, A. (2018). "Yo quería ser...": la voz de maestras de educación primaria. Ciencia y Educación, 2(1), 51-59. http://dx.doi. org/10.22206/cyed.2018.v2i1.pp51-59

Huerta, R. (2012). Mujeres Maestras. Identidades docentes en Iberoamérica. Editorial Graó.

Huerta, R. (Coord.) (2018). Mujeres maestras del Perú. Ediciones de la Pontificia Universidad Católica del Perú.

Huerta, R. (2019). Arte para primaria. UOC.

Huerta, R. (2020). El diseño de letras como entorno visual para educar en diversidad, ArtsEduca, (25), 5-22. http://dx.doi.org/10.6035/Artseduca.2020.25.1

Huerta, R., Alonso-Sanz, A. y Ramon, R. (eds.). (2018). Investigar y educar en diseño. Tirant lo Blanch.

Huerta, R., Domínguez, R. y Barbosa, A. M. (2017). Investigar para educar en diseño y otras urgencias de la educación artística. EARI Educación Artística Revista de Investigación, (8), 10-23. https://doi.org/10.7203/eari.8.10790

Kunhardt, E. (2020). Invención dentro del curriculum: sugerencias de un innovador. Ciencia y Educación, 3(3), 43-52. https://doi.org/10.22206/ cyed.2019.v3i3.pp43-52

Melo de Lima Santos, Z. M. (2017). Escola como espaço de transformação: a articulação da educação, pobreza e desigualdade social no currículo escolar. Revista Internacional de Investigación en Ciencias Sociales, 13(2), 239-252. http://dx.doi. org/10.18004/riics.2017.diciembre.239-252

Méndez, P. (2016). Constitución de sujeto maestro en prácticas de resistencia en Colombia. Enunciación, 21(1), 15-30.

Monterroza Montes, V., Buelvas Solórzano, U. J. y Urango Arrieta, J. (2019). Arte, creatividad y cultura en infantes. Ciencia y Educación, 3(2), 37-46. https://doi.org/10.22206/cyed.2019. v3i2.pp37-46

Ramon, R. (2019). Prácticas artísticas de visualización entre cuerpo y objeto en entornos de mediación pedagógica. Arte, Individuo y Sociedad, 31(13), 509-526. http://dx.doi.org/10.5209/aris.60881 
Rivas, J. I., Hernández, F., Sancho, J. M. (coord.) (2012). Historias de vida en educación: Sujeto, Diálogo, Experiencia. Universitat de Barcelona. Rolling, J. H. (2017). Arts-Based Research in Education. En Leavy, P. (ed.) Handbook of Arts-Based Research. Guilford, 493-510.

Secretaría Nacional de Cultura (2016). Más allá de la Guerra. Aportes para el debate contemporáneo. Ocaso Ediciones.
Stake, R. E. (2005). Investigación con estudio de casos. Ediciones Morata.

Zafra, R. (2017). El entusiasmo. Precariedad y trabajo creativo en la era digital. Editora Anagrama. 